\title{
A global climatology of atmospheric fronts
}

\author{
Gareth Berry, ${ }^{1}$ Michael J. Reeder, ${ }^{1}$ and Christian Jakob ${ }^{1}$ \\ Received 9 December 2010; revised 13 January 2011; accepted 19 January 2011; published 25 February 2011.
}

[1] Atmospheric fronts in the lower troposphere often mark regions of significant weather and serve as an important conceptual tool that is frequently used and well understood by the public. This study uses an objective method to identify fronts in the ERA-40 reanalysis and to compile a quantitative global climatology of their occurrence. The climatology confirms the mid-latitude storm tracks as the regions of highest front frequency and identifies slow moving frontal boundaries in the subtropics corresponding to major climate features, such as the Mei$\mathrm{Yu}$ front. The climatology also shows fronts to be common features of the South Pacific convergence zone. In the northern hemisphere fronts shift poleward in summer. In the southern hemisphere this and other aspects of seasonal behavior are rather different. Citation: Berry, G., M. J. Reeder, and C. Jakob (2011), A global climatology of atmospheric fronts, Geophys. Res. Lett., 38, L04809, doi:10.1029/2010GL046451.

\section{Introduction}

[2] The concept of an atmospheric front, which has been the mainstay of synoptic meteorology since its introduction in the first half of the twentieth century [Bjerknes and Solberg, 1922], remains today a succinct method of summarizing weather conditions. Although the term front simply refers to the interface between air masses of different thermal characteristics, such interfaces are frequently associated with significant weather, e.g., precipitation, abrupt changes in temperature etc. Because fronts are closely connected to the local weather conditions and are simple to depict graphically on a map, they are used to communicate information among forecasters and also from forecasters to the public. It is surprising that despite such common use, to our knowledge, no comprehensive climatology of fronts currently exists in the literature. The aim of this research is to address this omission by applying an objective detection algorithm to a global atmospheric reanalysis dataset to construct a self-consistent annual and seasonal climatology of fronts in the lower troposphere.

[3] It is possible that the paucity of published frontal climatologies is because frontal analysis at operational centers traditionally is conducted manually. This manual process, local interests and emphasis, along with the lack of a precise definition introduces a high degree of subjectivity into the analysis of fronts. Such inconsistencies, coupled with the graphical depiction of fronts as discontinuous line segments on a map means that compiling a meaningful climatology from synoptic charts is not practical. An alter-

\footnotetext{
${ }^{1}$ Monash Weather and Climate, Monash University, Clayton, Victoria, Australia.

Copyright 2011 by the American Geophysical Union. 0094-8276/11/2010GL046451
}

native method that will be employed here is to use a computer algorithm to automatically detect and draw fronts using gridded datasets. Such an approach is not new; many studies from the 1960's onward have developed methods of objectively drawing the locations of fronts from Numerical Weather Prediction (NWP) datasets, with varying degrees of success (see the summary of Hewson [1998, hereafter H98]). All these objective methodologies use some thermodynamic variable from a NWP model to compute and plot the possible locations of fronts, which can then be used by an analyst as guidance. Prior to H98, the objective methods generally identified broad scale frontal regions and lacked the capacity to separate fronts into warm or cold. H98 presented a graphical method of precisely locating fronts in NWP data, identifying their type and plotting them as colored line segments.

[4] In the research reported here, the same objective frontal diagnostics of $\mathrm{H} 98$ are used with an additional algorithm that allows the calculation of an objective, selfconsistent and repeatable global climatology of fronts using a reanalysis dataset.

\section{Methodology and Dataset}

[5] The methods derived by $\mathrm{H} 98$ rely on the computation of several functions from a thermodynamic variable and the horizontal winds on an isobaric surface in a gridded dataset. These algorithms are designed to automatically plot fronts on a synoptic chart through the use of graphical masks. Here, the same basic methodology is adopted, except that the masking is done numerically and a line-joining algorithm is employed to group contiguous points into individual fronts. This algorithm joins frontal points to their nearest neighbor if the two points are separated by less than five degrees. Fronts comprising less than three points are removed.

[6] This procedure is applied to the European Centres for Medium range Weather forecasts (ECMWF) ERA-40 reanalysis [Uppala et al., 2005]. The data used here have a spatial resolution of $2.5^{\circ} \times 2.5^{\circ}$ and span the period January 1958 to December 2001 at 6-hour intervals. Various choices of thermodynamic variable were examined but, in agreement with $\mathrm{H} 98$, the wet bulb potential temperature $\left(\theta_{\mathrm{w}}\right)$ at $850 \mathrm{hPa}$ provided the closest match to the manually prepared synoptic analyses (although most thermodynamic fields gave sensible results).

[7] As noted by H98, threshold values must be selected for the minimum intensity of the thermal front parameter (TFP; defined by Renard and Clarke [1965]) used to define fronts and the front speed to differentiate between types of front. The TFP threshold was selected by computing the mean magnitude of this quantity between $70^{\circ} \mathrm{N}$ and $70^{\circ} \mathrm{S}$ during 2001; the threshold was set at the negative of this value $\left(-8 \mathrm{~K} \mathrm{~m}^{-2}\right)$. Although $\mathrm{H} 98$ uses a front speed of $0 \mathrm{~ms}^{-1}$ to differentiate between cold and warm fronts, our preliminary 

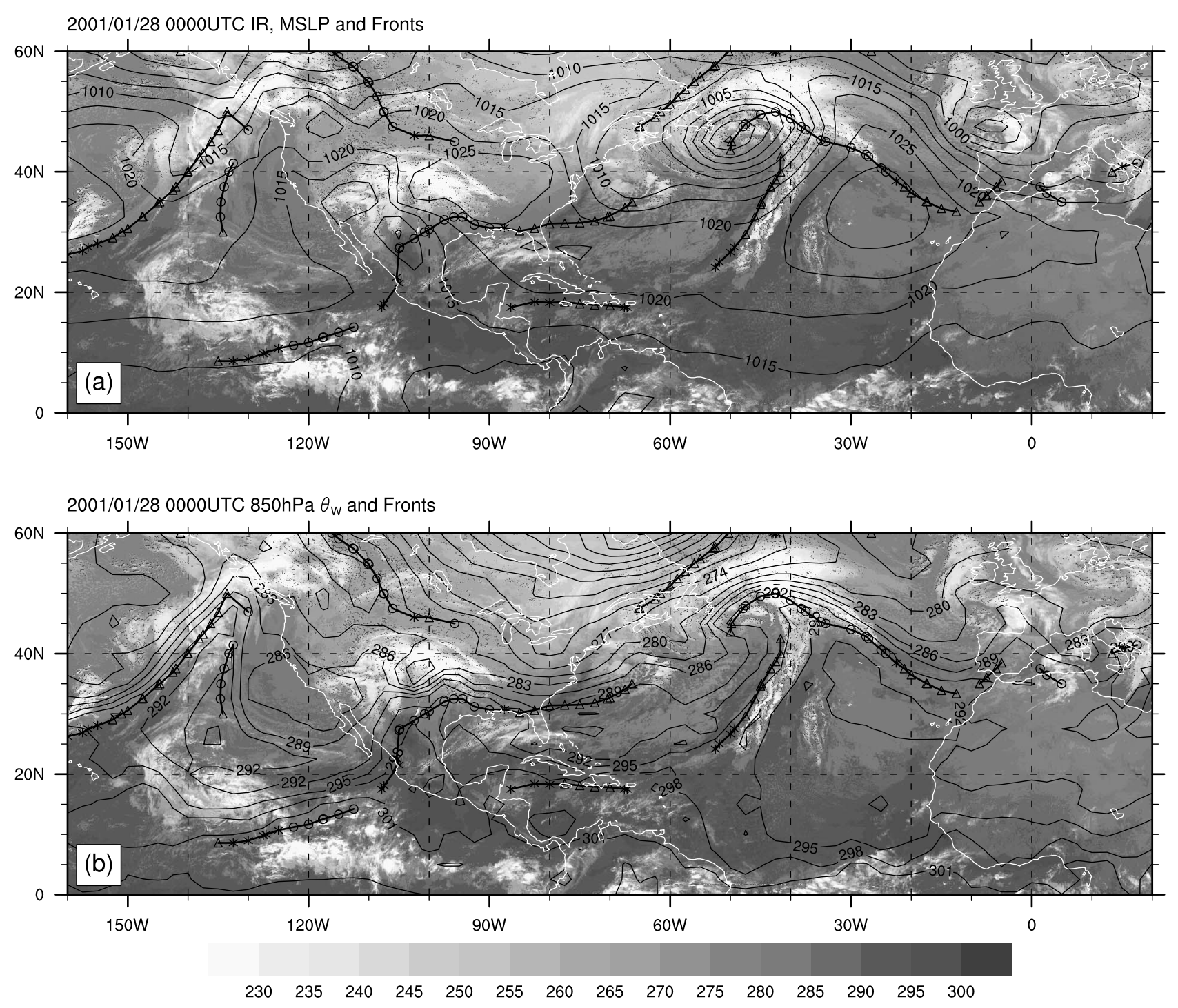

Figure 1. Example time from ERA- 40 dataset showing objective fronts at $850 \mathrm{hPa}$ plotted over infrared satellite imagery (shaded in K, according to scale at base) and (a) mean sea level pressure (solid contours drawn every $5 \mathrm{hPa}$ ) and (b) $850 \mathrm{hPa}$ $\theta_{\mathrm{w}}$ (solid contours drawn every $3 \mathrm{~K}$ ). Front locations are indicated by thick line with triangle, circle and star symbols indicating cold, warm and quasi-stationary front locations, respectively.

analysis suggested that there are regions of the globe where slow moving fronts are commonplace. To analyze these separately it was elected to use two threshold speeds to separate fronts into three types. The mean magnitude of the frontal speed parameter of $\mathrm{H} 98$ was computed between $70^{\circ} \mathrm{N}$ and $70^{\circ} \mathrm{S}$ during 2001 and, based on this, warm fronts were defined as fronts occurring where the frontal speed parameter exceeded $1.5 \mathrm{~ms}^{-1}$, cold fronts where the parameter was less than $-1.5 \mathrm{~ms}^{-1}$, otherwise the fronts were defined as quasi-stationary.

[8] To check that the objective fronts generated from the ERA-40 dataset with these thresholds produces sensible results, several week-long periods in each season of 2001 were subjectively compared with manually prepared charts from the Australian Bureau of Meteorology, the UK Met Office and the US National Weather Service, with good agreement. To demonstrate that the technique produces viable results with the $2.5^{\circ} \times 2.5^{\circ}$ ERA-40 reanalysis, Figure 1a shows the automatically generated objective fronts for an example time. The objective fronts are overlaid on mean sea level pressure (MSLP) and an infrared image, neither of which are used in the objective analysis. The $850 \mathrm{hPa} \theta_{\mathrm{w}}$ field used to derive these objective fronts is included in Figure 1b for reference. Even though the reanalysis used is relatively coarse, the objective fronts are closely aligned with features that one may recognize from synoptic experience. In particular, the fronts lie close to troughs in the surface isobars and the cloud features associated with baroclinic cyclones. Concurring with H98 and references therein, we find that these objective diagnostics give a reliable representation of frontal locations that is comparable to their manually generated equivalent.

\section{Results}

[9] The automatic frontal detection algorithm is applied to the entire ERA-40 dataset and a climatology of frontal activity generated. Figure 2 shows the annual mean front 

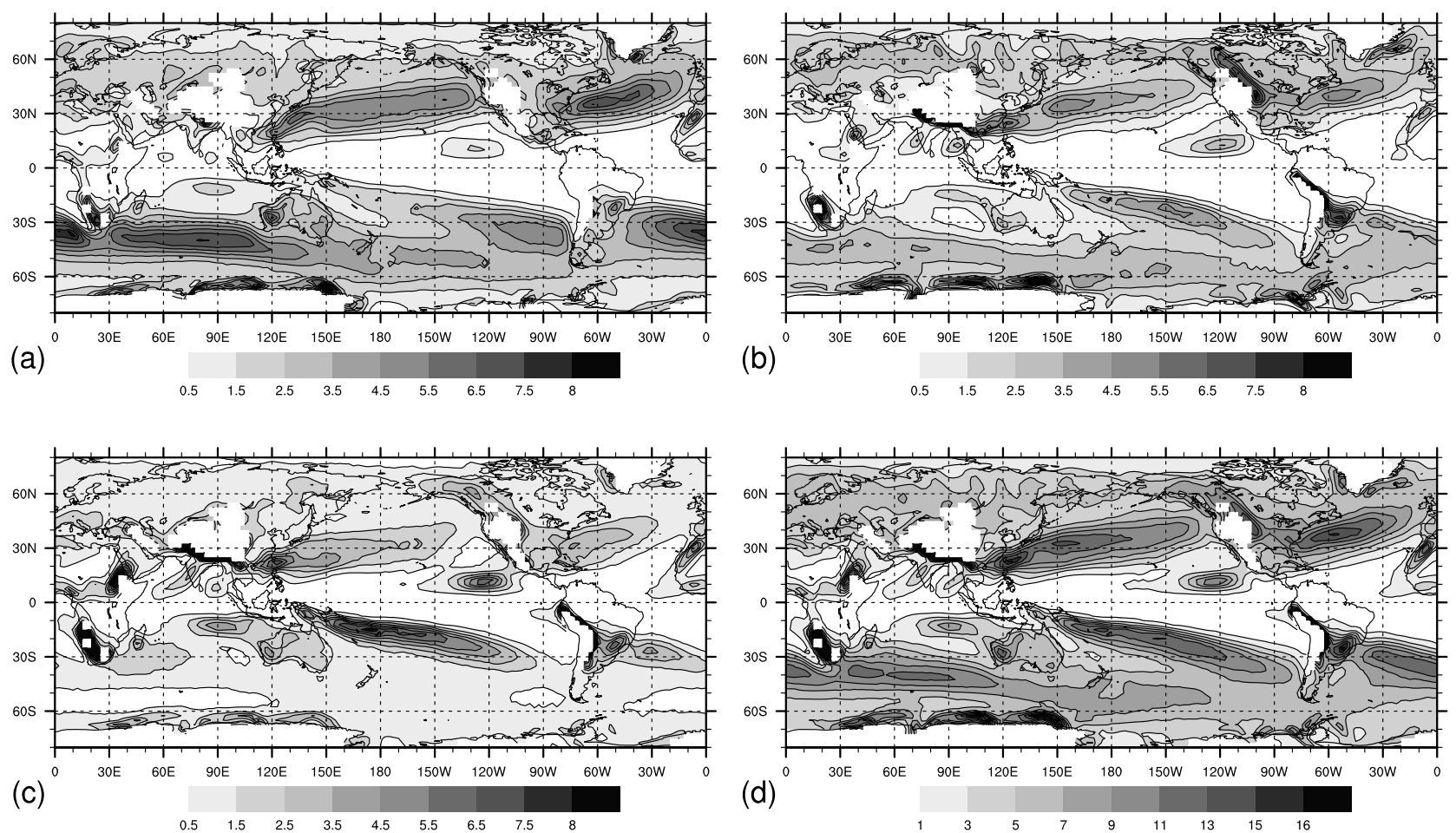

Figure 2. Annual mean front frequency of (a) cold (b) warm (c) quasi-stationary and (d) the sum of all fronts in the ERA40 reanalysis. Units are percentage time at which an objectively identified front was located within each grid box. Scales are displayed under each panel.

frequency (expressed as a percentage of time) for the three types of front and their sum. Regions where the height of the topography is greater than $1.5 \mathrm{~km}(850 \mathrm{hPa}$ in the standard atmosphere) are masked out. The largest values of front frequency are of order $10 \%$, as fronts are generally associated with synoptic scale transient weather systems. Consistent with conventional synoptic experience, the front frequency is low near the equator, increases in the subtropics and peaks in the mid latitudes. There are large values also at high latitudes in both hemispheres and near high terrain (e.g., the North American Rockies and coastal regions of Greenland and Antarctica). Further analysis indicates that the corresponding features are real boundaries in $\theta_{\mathrm{w}}$, but are often not fronts in the meteorological sense used here. These maxima are largely due to persistent baroclinic zones connected with a change in the underlying land surface (e.g., the edge of Antarctic ice pack), or the underlying sloping topography, where the $850-\mathrm{hPa}$ level intersects strong gradients in temperature and moisture associated with the boundary layer. These baroclinic zones do have a role in the generation of cyclones in some instances but are not the focus of this study and are not highlighted further.

[10] Some of the highest front frequencies are found in the mid-latitude storm tracks over the oceans and are approximately co-located with the maxima in coherently tracked cyclonic vorticity centers reported by Hodges et al. [2003]. This concurs with other front climatologies [e.g., Reed and Kunkel, 1960; Serreze et al., 2001], which increases confidence in these results. Overall, the warm front maxima tend to occur poleward of the cold front maxima, consistent with the net poleward transport of warm, moist air in the storm tracks. Quasi-stationary fronts tend to be less common in the oceanic storm tracks and are located further equatorward than the cold front maxima. While overall the quasistationary front maxima tend to have smaller scale, significant maxima coincide with the locations of some important regional phenomena, particularly in the subtropics, such as the Mei-Yu front near Taiwan and the South Pacific Convergence Zone (SPCZ).

[11] The maxima in combined front frequency (Figure 2d) in the Northern Atlantic and Northern Pacific are similar; the maximum values are found on the western side of the basins and the maxima are orientated WSW-ENE, consistent with the poleward movement of extratropical cyclones in the mean westerlies. In the Southern Hemisphere (SH) the largest frequency maximum extends from the South Atlantic, through the Indian Ocean and into the Southern Pacific Ocean, passing south of New Zealand. In the South Pacific there is a second maximum that extends from Papua New Guinea towards Chile, with peak values located in the west of the frequency maximum. Unlike the other SH maxima, this second maximum in the South Pacific is not associated with a well-defined storm track at the surface [Simmonds and Keay, 2000] or mid troposphere [Piva et al., 2008] and is associated with the global maximum in quasi-stationary fronts. This maximum is co-located with a region of maximum frontogenesis at $850 \mathrm{hPa}$ found by Satyamurty and De Mattos [1989] and the SPCZ [see Vincent, 1994].

[12] The seasonal variation in both cold and warm front frequency is shown by the 3-month means plotted in Figure 3. In the Northern Hemisphere (NH) there is a well-defined seasonal shift in the locations of the cold and warm front frequency maxima, which reach their lowest latitudes during the winter months over the oceans. The seasonal shift in the $\mathrm{SH}$ is not as well defined as that in the $\mathrm{NH}$; notably the maxima related to the midlatitude storm track remains more 

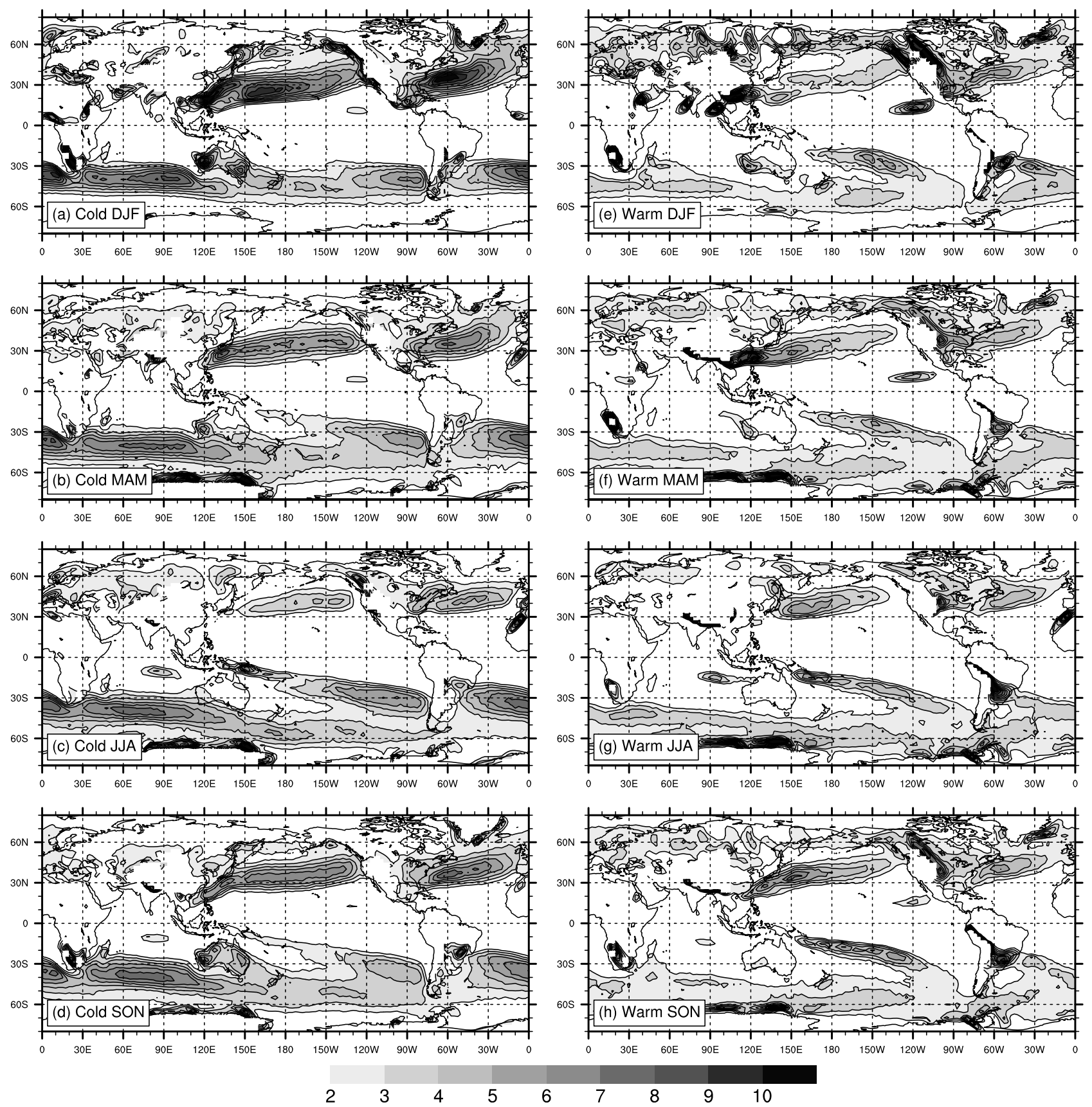

Figure 3. Mean seasonal evolution of $(a-d)$ cold and $(e-h)$ warm front frequency. Units are percentage of time at which an objectively identified front was located within each grid box during the 3-month periods. Scale is displayed at base of figure.

or less fixed through the year. The largest seasonal variations over the SH oceans are associated with the SPCZ frequency maxima that migrate poleward during the warm season. Over the $\mathrm{SH}$ continents localized front maxima occur over Australia and southern Africa during the warm season, in association with an increase in non-precipitating fronts (see discussion). Seasonal peaks in front frequency do not vary so coherently across in the $\mathrm{NH}$; for example, warm front activity in the North Atlantic peaks during winter (Figure 3e), whereas in the North Pacific it is then at a clear minimum. A measure of the seasonal variability can be obtained by computing seasonally and spatially averaged front frequencies in each hemisphere and com- paring the least active with the most active seasons. Consistent with the notion that the $\mathrm{NH}$ is more variable between seasons, the overall least active season in the $\mathrm{NH}$ (JJA) has 44\% fewer cold fronts and 38\% fewer warm fronts than the overall most active season (DJF), whereas in the $\mathrm{SH}$ there are only $27 \%$ fewer cold fronts and $23 \%$ fewer warm fronts between the most (JJA) and least (DJF) active seasons.

\section{Discussion}

[13] The application of the automated frontal detection algorithms to ERA-40 highlights the oceanic storm tracks as regions of high frontal frequency, which is expected from 
conceptual models of mid-latitude cyclones. Near the SPCZ there is no well-defined storm track, but there is a welldefined maximum in front frequency (particularly quasistationary fronts) throughout the year that is separate from the higher latitude storm tracks. This may be associated with the in-situ formation of frontal boundaries by deformation within the SPCZ rather than baroclinic cyclones. This is supported by the study of Kuhnel [1989], who reports that this region has the highest annual number of cloud bands.

[14] On the southern portions of the SH continents (near $30^{\circ} \mathrm{S}$ ) there are localized frontal frequency maxima. These are separate from the storm tracks but are co-located with maxima in $850-\mathrm{hPa}$ frontogenesis as reported by Satyamurty and De Mattos [1989]. Using the ERA-40 rainfall as a guide, further analysis indicates that these fronts have little or no rainfall, and consequently are best described as dry fronts. Although we expect the ERA-40 rainfall analysis to have large uncertainties, the approximate proportion of wet and dry fronts was explored by stratifying all the identified frontal points dependent on rainfall at the closest grid point in the ERA-40 reanalysis. It was found that in the oceanic storm tracks there are no regions where more than $40 \%$ of the frontal points are dry (typical values near the front frequency maxima are less than 10\%). However, over southern Australia and western South Africa dry frontal points comprise around $70 \%$ of the total. Although the features that these maxima represent cover a relatively small area, they can be important regionally (e.g., in the context of Australian wildfires).

\section{Conclusions}

[15] Using an objective method to identify fronts in gridded datasets, a quantitative climatology of fronts has been constructed using the 44-year ERA-40 reanalysis. The primary diagnostic, which is an extension of the graphical method described by H98, was able to detect features in the ERA-40 dataset that closely resemble manual subjective representations of fronts. Frontal frequencies are maximized within the mid-latitude storm tracks with the relative locations of warm, cold and quasi-stationary front frequency maxima dynamically consistent with conceptual models of mid-latitude cyclones and heat transport.

[16] The analysis has revealed a hemispheric asymmetry in the distribution of fronts, with highest front frequencies in the NH in the Pacific and Atlantic Ocean basins, with local maxima occurring over the warm ocean currents on the western side of these basins. Presumably because the landsea distribution around the South Pole is more axisymmetric than it is around the North Pole, the SH frontal frequency distribution is dominated by a maximum that extends around most longitudes, following the observed storm tracks. Local frequency maxima due to the presence of non-precipitating fronts are found on the southern parts of the SH continents.
One of the most intriguing findings is the significant maximum in frontal frequency that occurs near the SPCZ in the absence of a well-defined storm track. It is probable that deformation is sufficient to generate fronts along moisture plumes between the tropics and extratropics in this region.

[17] A clear priority for future work is analyzing the recent trends in front frequency and comparing the results from the ERA-40 with other reanalyses. The overall success of the objective identification scheme applied on a relatively coarse grid would support the application of the technique to global climate models, both in verifying benchmark simulations of the current climate and as a diagnostic in future predictions.

[18] Acknowledgments. This work is supported by Australian Research Council grant DP0985665 "Rainfall over the Maritime Continent and Northern Australia". Data were provided by the European Centre for Medium-Range Weather Forecasts.

[19] Paul D. Williams thanks two anonymous reviewers.

\section{References}

Bjerknes, J., and H. Solberg (1922), Life cycles of cyclones and the polar front theory of atmospheric circulation, Geofys. Publ., 3, 1-18.

Hewson, T. D. (1998), Objective fronts, Meteorol. Appl., 5, 37-65, doi:10.1017/S1350482798000553.

Hodges, K. I., et al. (2003), A comparison of recent reanalysis datasets using objective feature tracking: Storm tracks and tropical easterly waves, Mon. Weather Rev., 131(9), 2012-2037, doi:10.1175/15200493(2003)131<2012:ACORRD>2.0.CO;2.

Kuhnel, I. (1989), Tropical-extratropical cloudband climatology based on satellite data, Int. J. Climatol., 9(5), 441-463, doi:10.1002/ joc.3370090502.

Piva, E. D., et al. (2008), An objective study of 500-hPa moving troughs in the Southern Hemisphere, Mon. Weather Rev., 136(6), 2186-2200, doi:10.1175/2007MWR2135.1.

Reed, R. J., and B. A. Kunkel (1960), The Arctic circulation in summer, J. Meteorol., 17, 489-506.

Renard, R. J., and L. C. Clarke (1965), Experiments in numerical objective frontal analysis, Mon. Weather Rev., 93, 547-556, doi:10.1175/15200493(1965)093<0547:EINOFA >2.3.CO;2.

Satyamurty, P., and L. F. De Mattos (1989), Climatological lower tropospheric frontogenesis in the midlatitudes due to horizontal deformation and divergence, Mon. Weather Rev., 117, 1355-1364, doi:10.1175/ 1520-0493(1989)117<1355:CLTFIT>2.0.CO;2.

Serreze, M. C., A. H. Lynch, and M. P. Clark (2001), The summer Arctic frontal zone as seen in the NCEP/NCAR reanalysis, J. Clim., 14, 15501567, doi:10.1175/1520-0442(2001)014<1550:TAFZAS >2.0.CO;2.

Simmonds, I., and K. Keay (2000), Mean Southern Hemisphere extratropical cyclone behavior in the 40-year NCEP, NCAR reanalysis, J. Clim., 13(5), 873-885, doi:10.1175/1520-0442(2000)013<0873: MSHECB $>2.0 . \mathrm{CO} ; 2$.

Uppala, S. M., et al. (2005), The ERA-40 re-analysis, Q. J. R. Meteorol. Soc., 131(612), 2961-3012, doi:10.1256/qj.04.176.

Vincent, D. G. (1994), The South Pacific convergence zone (SPCZ): A review, Mon. Weather Rev., 122, 1949-1970, doi:10.1175/1520-0493 (1994)122<1949:TSPCZA>2.0.CO;2.

G. Berry, C. Jakob, and M. J. Reeder, Monash Weather and Climate, Monash University, Clayton, Vic 3800, Australia. (gareth.berry@sci. monash.edu.au) 